\title{
Exercise stress testing in clinical practice
}

Il test da sforzo nella pratica clinica

Francesco Giallauria ${ }^{1}$, Alessandra Grieco ${ }^{1}$, Angelo Russo ${ }^{1}$, Luigi Maresca ${ }^{1}$, Maria Mancini ${ }^{1}$, Alessandra Vitelli ${ }^{1}$, Sara Aurino ${ }^{2}$, Carlo Vigorito ${ }^{1}$

1 Department of Clinical Medicine, Cardiovascular and Immunological Sciences, Cardiac Rehabilitation Unit, Università di Napoli "Federico II", Napoli (Italy)

2 Department of Preventive Medicine, Università di Napoli "Federico II", Napoli (Italy)

\section{Abstract}

Exercise stress testing is an important diagnostic tool for evaluating patient's cardiovascular performance. The present review describes the accuracy and the value of exercise stress testing in different settings: after an acute coronary event, after percutaneous coronary intervention or coronary artery bypass graft; in patients risk assessment before non-cardiac surgery; in diabetic population; in patients with baseline electrocardiographic abnormalities. Moreover, this review provides insights relating to test accuracy in women and geriatric patients. Finally, this review explores new variables/parameters (dyspnea, chronotropic incompentence, heart rate recovery, functional capacity, integrated scores) that in the last few years added an incremental value to conventional analysis of exercise-induced angina or electrocardiographic changes.

\section{Keywords}

Exercise stress testing; Acute coronary event; Percutaneous coronary intervention; Coronary artery bypass graft; Dyspnea; Chronotropic incompentence; Heart rate recovery; Functional capacity; Women; Elderly

Corresponding author Francesco Giallauria, MD, PhD

Cardiac Rehabilitation Unit

Università di Napoli "Federico II"

Via Pansini 5

80131 Napoli (Italy)

Email: giallauria@libero.it
Disclosure

The authors declare that they have no financial competing interests 


\section{Exercise stress testing after acute coronary event}

The current American College of Cardiology (ACC) and American Heart Association (AHA) guidelines recommend submaximal or low-level ExT as early as 3-5 days after an uncomplicated coronary event prior to discharge unless the patient has undergone percutaneous coronary intervention (PCI) or coronary artery bypass graft (CABG) surgery and been fully revascularised [1].

Maximal symptom-limited ExT can be performed 30 days after the coronary event. The submaximal exercise test is stopped when one of the following endpoints occurs:

- peak heart rate of 120 to 130 beats per minute or $70 \%$ of the maximal predicted heart rate for age;

- peak work level of 5 metabolic equivalents (METs);

- mild angina or dyspnea;

- exercise-induced ST-segment depression of $2 \mathrm{~mm}$ or more;

- exertional hypotension; or

- hree or more consecutive ventricular premature contractions.

Usually, if a patient is able to complete a stress test at an acceptable cardiovascular workload ( 5 or more METs) without any ECG changes, angina, hypotension, significant ST-segment depression or frequent ventricular premature contractions, he/she is deemed low-risk for a recurrent cardiac event during the next year [2].

Karlson et al showed that among patients hospitalised with a suspected or confirmed acute ischemic event but either no or only minor myocardial necrosis, the maximum working capacity at a symptomlimited ExT was independently associated with the long-term prognosis but not with other signs of myocardial ischemia [3]. Moreover, further predictors for long-term prognosis were age, a history of acute myocardial infarction, current smoking, and diabetes mellitus. Interestingly, mechanical revascularisation during the subsequent 5 years interacted with the influence of symptoms of angina during test and prognosis.

If the patient presents resting ECG abnormalities which preclude interpretation of exercise-induced ischemia, the addition of nuclear imaging as well as echocardiography is suggested. However, there is a general agreement that performing a symptom-limited ExT after an acute myocardial infarction (MI) using the Bruce protocol 3 days after admission determines a very low incidence of complications [46]. A meta-analysis showed that if the pre-discharge ExT is normal following an acute MI, there is a $<$ $10 \%$ event rate at 1 year; if abnormal, the event rate increased to $10-20 \%$ [7]. Postinfarction functional capacity is also crucial: the ability to achieve an adequate cardiac workload (pressure rate product higher than 21,700 ) has been associated with an efficient myocardial blood supply and with a favorable 6-month prognosis [8].

\section{Exercise stress testing after percutaneous coronary intervention}

In patients who have undergone recent Percutaneous Coronary Intervention (PCI), recurrence of symptoms itself has low sensitivity and specificity for detecting restenosis and myocardial ischemia. ExT may provide useful information on symptoms and functional capacity of the patient; however, a meta-analysis showed that ExT alone has a poor sensitivity (46\%) and a moderate specificity (77\%) for the identification of post-PCI restenosis [9].

The use of nuclear imaging increases the sensitivity to $83 \%$ without affecting specificity [10]. In addition, ExT with imaging adds incremental information (ejection fraction and wall motion) and is useful to localise the region of ischemia as well as assists the interventionalist in identifying the culprit lesion [11-13]. Of note, symptom-limited ExT the day after stent implantation is safe [14]. 
In the first month post-PCI, an abnormal ExT may indicate inadequate intervention or revascularization result, or a successful result with impaired coronary flow reserve in the site [15].

Therefore, for routine follow-up in asymptomatic patients, it has been suggested to perform an ExT with imaging 2-3 months after PCI in order to avoid false positive results. At that epoch, ExT is useful to diagnose restenosis or new stenosis in asymptomatic patients as well as document functional capacity and aid in early identification of patients at risk for subsequent events [16].

\section{Exercise stress testing after coronary artery bypass graft}

In order to allow sternal healing and appropriate early rehabilitation, there is a general agreement on waiting 2-3 months after surgery before doing a symptom-limited ExT. In post-coronary artery bypass graft (post-CABG) patients with an abnormal baseline ECG which are non-diagnostic for ischemia, an imaging modality should be added. Exercise-induced ischemic ST-segment depression may persist when incomplete revascularisation is achieved, as well as in $5 \%$ of patients who have had complete revascularisation $[17,18]$. The sensitivity as well as the prognostic value of the test is greater in the late period (5-10 years after CABG) than in the early period (first year after CABG) [19,20].

\section{Exercise stress testing in risk assessment before non-cardiac surgery}

ExT is useful to identify coronary artery disease (CAD) in asymptomatic patients, especially in those who do not exercise regularly, or to stratify cardiovascular risk in patients with known CAD prior to non-cardiac surgery. Findings which increase risk of perioperative cardiac events include marked exercise-induced ST-segment depression or exercise-induced angina at low workloads, poor exercise capacity ( $<5 \mathrm{METs})$, an abnormally low peak systolic blood pressure $(<130 \mathrm{mmHg})$, or a fall in systolic blood pressure during exercise $>10 \mathrm{mmHg}$ below standing rest values [21,22].

According to 2007 ACC/AHA guidelines, continued emphasis should be given to preoperative clinical risk stratification, with noninvasive testing reserved for those patients in whom a substantial change in medical management would be anticipated based on results of testing [23]. Moreover, the implementation of the ACC/AHA guidelines for cardiac risk assessment prior to non-cardiac surgery in a consultant anaesthesiologist-led preoperative clinic reduced preoperative resources utilization, improved medical treatment and preserved a low rate of perioperative cardiac complications [24].

Notably, in clinical practice, ExT have a poor positive predictive value for identifying which patients will have a perioperative cardiac event, suggesting that perioperative MI's may not share the same pathophysiology as non-operative MI's [25,26]. In addition, patients with functional limitations such as arthritis or other medical problem will likely require an alternative form of stress test such as a pharmacological nuclear or echocardiographic stress test. To reduce the risk of these complications, some Authors have reported on the utility of intraoperative transesophageal echocardiography as a complementary monitoring tool in non-cardiac surgery. However, although this approach is now well established in patients undergoing cardiac surgery, there are no guidelines for intraoperative transesophageal echocardiography application in non-cardiac surgery, and little literature exists on patient outcome, logistics, financial impact, medico-legal implications and safety [27]. Finally, taking into consideration the higher risk of coronary angiography and revascularisation in high-risk patients, the current approach is moving away from extensive noninvasive preoperative risk stratification towards selective noninvasive testing and aggressive pharmacological peri-operative therapy [28]. 


\section{Exercise stress testing in diabetic patients}

Coronary artery disease is the leading cause of morbidity and mortality in patients with diabetes mellitus [29]. In fact, patients with diabetes have the same risk of myocardial infarction as do non-diabetic subjects with a history of infarction. For this reason, diabetes should be considered as a CAD equivalent [30].

Current diagnostic tools include ExT, stress echocardiography, stress myocardial perfusion imaging, and cardiac catheterisation [31]. Although cardiac catheterisation is useful, it is generally reserved for patients in whom invasive intervention is suitable. The American Diabetes Association (ADA) recommends ExT alone in symptomatic patients with 2 or more CAD risk factors or an abnormal resting ECG. Stress echocardiography is a useful, noninvasive procedure; however, there is limited experience with this technology in the diabetic population. Recently accumulated data support both diagnostic and prognostic roles for stress myocardial perfusion imaging, particularly with ECG-gated single-photon emission computed tomographic imaging. In symptomatic patients with diabetes, the presence and extent of abnormal stress myocardial perfusion imaging findings have been found to be highly accurate independent predictors of subsequent cardiac events: $18 \%$ to $26 \%$ of asymptomatic patients with diabetes have perfusion defects consistent with CAD. However, cardiovascular risk factors are not predictive of abnormal stress myocardial perfusion imaging findings even though duration of diabetes and abnormal ECGs are. A recent study showed that in diabetic asymptomatic patients, combining a myocardial scintigraphy with a maximal ECG stress test is effective in detecting more patients with coronary stenoses and predicting cardiovascular events [32]. However, ExT has a good negative predictive value for cardiac events (97\%), is cheaper, and should therefore be proposed first [32].

Finally, related issues specific to diabetic patients undergoing ExT include:

- similar diagnostic sensitivity and specificity of ExT for identification of CAD in patients presenting with angina;

- lower diagnostic accuracy in asymptomatic diabetics, who may not manifest angina;

- reduced functional capacity, associated with increased cardiac morbidity and mortality;

- abnormal HRR.

\section{Exercise stress testing in geriatric patients}

The ever-increasing number of older patients requiring diagnostic and prognostic assessment for CAD has necessitated accurate, noninvasive techniques applicable to this age group [33]. Exercise electrocardiography is more challenging in the elderly. Elderly subjects are more likely to have baseline ECG abnormality rendering the ECG non-diagnostic [34]; and less likely to achieve adequate and diagnostic exercise workload due to arthritis, musculoskeletal disease, peripheral arterial disease, and reduced cardiopulmonary reserve [35]. Of note, in old population with higher prevalence of $\mathrm{CAD}$, a borderline exercise test is much more likely to indicate real disease than in a low-risk younger population. In elderly patients able to exercise, workload achieved is independently predictive of cardiac morbidity and mortality [36,37]. Although the performance of exercise stress testing may pose several problems in older patients, it is not contraindicated [38]. Recently, McAuley et al [39], using ExT in healthy elderly men, observed independent and joint inverse relations of body mass index and cardiorespiratory fitness to mortality, suggesting fitness and fatness as mortality predictors in these subjects. For those patients with a non-diagnostic ECG or not able to exercise or achieve an adequate workload, adjunctive imaging may determine the extent and severity of ischemia with more accuracy $[33,34]$. 


\section{Patients with left ventricular hypertrophy on their baseline ECG}

ExT has been demonstrated to be sensitive ( $68 \%$ vs. $72 \%$ ) but not so specific ( $69 \%$ vs. $77 \%$ ) for detecting CAD [40]. Most testing labs will require $\geq 2 \mathrm{~mm}$ of ST-segment depression in the presence of left ventricular hypertrophy by Sokolow-Lyon (voltage) criteria to report a significant ST-segment change [40]. The major reason behind the false positive ST-segment changes is the mild subendocardial ischemia secondary to concentric hypertrophy and microvessels, in the setting of relatively normal epicardial coronary arteries.

\section{Patients with a right bundle branch block on their baseline ECG}

Patients with right bundle branch block (RBBB) typically manifest wide QRS complexes and T wave inversion in precordial leads V1-V3 on their baseline ECG, so exercise-induced ST segment depression is non-diagnostic if it occurs in leads V1-V3 [40]. However, in the remaining leads, ST-segment changes are diagnostic for ischemia, with the resulting sensitivity and specificity being similar to a patient with a normal baseline ECG. Therefore, it is still considered appropriate to perform ExT without imaging as an initial test in patients with RBBB.

\section{Exercise stress testing in women}

In women, sensitivity (61\%) and specificity (69\%) of ExT for detecting CAD using ST-segment changes or exertional angina are significantly less than for men [41]. However, low exercise capacity, abnormal HRR, inability to achieve target heart rate, and integrative scores were independently associated with increased cardiovascular and total mortality. Several reasons for the lower test accuracy in women should be considered. Women have a lower exercise capacity and achieve target heart rate less often than age-matched men [41]. Furthermore, women present with manifestations of CAD at an older age than men and thus unable to achieve as great a workload [42]. Women more often have resting ST-T changes and lower ECG voltage [41]. Finally, sex hormones (estrogen) can affect ST-segment changes and have a digoxin-like effect. Premenopausal women are more likely to have false positive ExT than postmenopausal women, and false positive tests occur more frequently when estrogen levels are high [43]. Postmenopausal women on hormone replacement therapy with estrogens showed an increase in false positive ischemic ST-segment depressions on ExT [44]. Women also present smaller coronary vessel size which may reduce the maximal flow heterogeneity and potentially decrease the amount of ST-segment changes. Finally, during the exercise portion of the ExT, women with moderate sized breasts may get excessive ECG motion artifact from the breasts pushing and pulling on adjacent skin and precordial ECG leads making it difficult to interpret ST-segment changes.

\section{Exercise stress testing in women with polycystic ovary syndrome}

Polycystic ovary syndrome (PCOS) is the most common endocrine disorder in premenopausal women, with 6-7\% prevalence worldwide, mainly characterised by chronic ovulatory dysfunction, insulin 
resistance and hyperandrogenism [45]. Metabolic-hormonal features observed in PCOS represent an intriguing biological model illustrating the relationship between hormonal pattern and cardiovascular risk profile [46]. PCOS women, even at an early age, have a clustering of cardiovascular features, such as obesity, low-grade inflammation and metabolic syndrome [46,47].

ExT represents a useful tool at evaluating cardiopulmonary functional capacity and autonomic function in PCOS women [48-50]. Further studies are strongly encouraged in order to investigate the prognostic value of ExT in this group of patients.

\section{Endpoints and post-exercise recovery}

Criteria for the achievement of appropriate workload during ExT are reported in the box.

The test's capacity for detecting significant CAD is reduced whether a patient is unable to reach any of these endpoints for whatever reason [40]. Certain occurrences during the test strongly suggest an immediate stop of the ExT and have the patient sit down and recover. These include development of significant angina $>10 \mathrm{mmHg}$ fall in systolic blood pressure, central nervous symptoms, signs of

Goals that the patient should achieve to obtain an adequate workload during ExT

- $85 \%$ of their maximal age-predicted heart rate, i.e. $0.85 \times(220-$ age of patient in years). This results in an increase in coronary blood flow of 2-4 fold in non-stenosed coronary arteries

- A pressure-rate product or double product of $>20,000$, chosen because a pressurerate product $>20,000$ results in an increase in coronary blood flow of 2-3 fold in non-stenosed coronary arteries

- An ischemic endpoint (i.e. reproduced patient's usual angina so that they wish to stop or significant ischemic ST segment changes). Exercise-induced ischemic ECG changes occur more frequently, and usually precede onset of angina decreased perfusion, ischemic ST-segment elevation $\geq 1.0 \mathrm{~mm}$ in leads without $\mathrm{Q}$ waves (other than V1 and aVR), ischemic ST-segment depression $\geq 3.0 \mathrm{~mm}$, equipment problems, request by patient to stop, or significant arrhythmia. Adverse findings during ExT which indicate future cardiac morbidity and mortality are shown in the box.

To note, the recovery stage is the only time where abnormalities manifest. Recovery continues until the patient's heart rate, systolic blood pressure, and ECG have returned to near baseline levels (usually within $9 \mathrm{~min}$ ). In addition, because the patient is resting in recovery, the ECG has a good baseline with minimal motion artifact. During recovery, patients can have major ischemic ECG changes even when the exercise

\section{Events that portend a poor prognosis during ExT}

- Poor exercise capacity (<5 METs)

- Abnormally low peak systolic blood pressure $(<130 \mathrm{mmHg}$ ) or a fall in systolic blood pressure during exercise of $10 \mathrm{mmHg}$ or more below standing rest values

- Exercise-induced angina, especially at low workloads

- $\geq 2 \mathrm{~mm}$ of ischemic ST-segment depression at a low workload ( $\leq$ Bruce stage 2 or heart rate $\leq$ 120 beats per minute)

- Early onset (Bruce stage 1) or prolonged duration (> $5 \mathrm{~min}$ ) ST-segment depression

- Multiple leads (5 or more) with ST-segment depression

- Exercise-induced ST-segment elevation (excluding aVR or leads with Q waves)

- Ventricular couplets, triplets, sustained (>30 s) or symptomatic ventricular tachycardia

- Abnormal HRR 
portion appeared normal. Also, tachy-arrhythmias including ventricular tachycardia and paroxysmal atrial fibrillation, or brady-arrhythmias such as second or third degree heart block, can occur.

\section{ST-segment depression and ventricular ectopy in the recovery phase}

The optimum ECG is more likely to be acquired early in recovery. Changes in recovery are just as significant for predicting risk for cardiac events (angina, MI, cardiac death) as those that occur during exercise [51]. Several studies showed that exercise-induced ventricular arrhythmias (defined as premature ventricular contractions $>10 \%$ of all ventricular depolarisation during any 30-s recording, or a run of three or more premature ventricular contractions during exercise or recovery) independently predict increased mortality [52]. One study of 29,244 men and women (mean age $=56$ years; $70 \%$ men) who had been referred for ExT (with no history of heart failure, valve disease, or arrhythmia) found that frequent ventricular ectopy ( $>7$ premature ventricular contractions/min, bigeminy, trigeminy, couplets, triplets, ventricular tachycardia, flutter, torsade, or fibrillation) during recovery but not during exercise was an independent predictor of increased morbidity and mortality [53]. Despite these studies, it remains unclear whether exercise-induced frequent ventricular ectopy is an independent predictor or a marker of underlying heart disease.

\section{Heart rate increase at the onset of exercise stress testing}

The initial response of heart rate to dynamic exercise has been proposed as having prognostic value in limited studies that have used modalities other than the treadmill.

In a study population of 1,959 patients referred for clinical ExT, Leeper et al [54] reported that decreased heart rate changes at all initial relative exercise workloads were associated with significantly increased all-cause mortality. Interestingly, the heart rate rise at one-third total exercise capacity, however, was the only early heart rate variable that significantly predicted both all-cause and cardiovascular risk after adjustment for confounders. The Duke Treadmill score, however, was superior to all heart rate measurements in the prediction of cardiovascular mortality.

\section{Heart rate recovery (HRR)}

During recovery, vagal reactivation results in increased parasympathetic tone and a decline in heart rate. This decline is blunted with decreased myocardial function and reduced exercise capacity. Multiple investigators have confirmed that abnormal HRR, defined as failure of heart rate to decrease 12 beats or more during the first minute after peak exercise (while the patient remains standing) independently predicts an increased mortality in men and women $[55,56]$. Further, the greater the fall in heart rate in the first minute of recovery, the lower the subsequent mortality. An abnormal HRR likely reflects decreased vagal reactivation, and has been directly related to abnormal heart rate variability and insulin resistance $[49,57,58]$. Patients with a HRR of less than 25 beats per minute likely have autonomic imbalance; in one cohort of middle-aged men, this independently predicted sudden death [59].

It should be noted that both chronotropic incompetence and HRR predict cardiovascular mortality in patients referred for exercise testing for clinical reasons [60].

Myers et al [60] reported that chronotropic incompetence was a stronger predictor of cardiovascular mortality than heart rate recovery, but risk was most powerfully stratified by these two responses together. These Authors suggested that the simple application of heart rate provides powerful risk stratification for cardiovascular mortality from the ExT, and should be routinely included in the test report [60].

\section{Systolic blood pressure recovery}

The systolic blood pressure should fall rapidly after cessation of exercise by more than $15 \%$ at $3 \mathrm{~min}$ after stopping; myocardial ischemia may delay this decline [61]. Abnormal systolic blood pressure 
recovery is significantly associated with severe CAD [62]. Laukkanen et al [61] reported that a systolic blood pressure $>195 \mathrm{mmHg}$ after exercise or a rise in systolic blood pressure of more than $10 \mathrm{mmHg} /$ min for 2 min after exercise was associated with risk of future MI.

\section{Exercise-induced bundle branch blocks and supraventricular arrhythmias}

Exercise-induced transient left bundle branch block occurs in about $0.4 \%$ of patients, renders the left bundle branch block (LBBB) portion of the ECG uninterpretable for ischemia, and in one series independently predicted a higher rate of death and major cardiac events [63]. However, if ischemic ST-segment changes occur before or after the left bundle branch block has resolved, the ExT is still sensitive for CAD. If a transient $L B B B$ develops at lower heart rates $\leq 120$ beats per minute or with classic angina, this may correlate with significant CAD (often proximal stenosis of the left anterior descending artery) [64]. In contrast, if the LBBB develops at rates $>120$ beats per minute it is more likely a rate-related phenomenon, and several studies have confirmed this to be associated with normal coronary arteries [64]. Exercise-induced transient RBBB is less common, occurring in about $0.1 \%$ of patients; a single study noted this was associated with CAD [64].

Supraventricular arrhythmias (atrial premature beats, atrial fibrillation, atrial flutter, supraventricular tachycardia) are commonly induced by exercise and seen in up to $10 \%$ of normals and in up to $25 \%$ of those with known or suspected CAD; they appear to be more common in patients with underlying heart disease. However, they are not diagnostic for CAD, nor do they predict adverse long-term cardiovascular outcomes [65].

\section{Scores, functional capacity, and new developments}

\section{Integrated treadmill scores}

Among the various scores that can be calculated based on traditional results as well as on other functional and hemodynamic aspects of the ExT that have prognostic value, the Duke Treadmill Score (DTS) is the most commonly used $[66,67]$. The DTS is easily calculated as follows:

$$
\text { DTS }=\text { Exercise time }-(5 \times \text { ST deviation })-(4 \times \text { Angina index })
$$

Where:

- Exercise time is calculated in minutes;

- ST deviation is the maximal exercise-induced ST-segment deviation in millimeters;

- Angina index is the exercise angina with $0=$ none, $1=$ non-limiting, $2=$ exercise limiting angina.

The DTS is then classified into risk as follows: low risk $\geq 5$, moderate risk -10 to +4 , and high risk $\leq-11$ $[66,67]$. Studies adopting the DTS score reported that CAD is more prevalent in men of all risk groups; however, amount and severity of disease increased from low risk to high risk in both genders as well as a higher mortality by all risk groups in men than women [66,67].

\section{Functional capacity and metabolic equivalents}

The metabolic equivalent is a unit of resting oxygen uptake which measures energy expenditure; 1 MET equals $3.5 \mathrm{ml}$ oxygen uptake $/ \mathrm{kg} / \mathrm{min}$. In studies of men and women referred for exercise testing, determination of exercise capacity in METs is a more powerful predictor of mortality than other established risk factors for cardiovascular disease [56,68]. Peripheral vascular endothelial function correlates with exercise capacity in both genders, even in the absence of CAD. Impaired functional capacity 
and abnormal HRR appear to be strongly and independently associated with lower socio-economic status $[69,70]$. Usually, major or sudden reductions in a patient's functional capacity (or MET level) should suggest further evaluation.

\section{ExT in cardiac rehabilitation programs and exercise prescription}

Cardiac rehabilitation in patients with CAD results in a substantial reduction in mortality and morbidity [71-73]. A typical outpatient cardiac rehabilitation program consists of weekly exercise for 12 weeks, allowing the development of an individualised exercise prescription that is safe and effective. The program should not improve the patients exercise capacity, but will also bolster confidence and psychological well-being, allow counseling on risk factor modification, and also establish a long-term exercise maintenance program [71-73]. According to AHA Guidelines, ExT should be used to risk stratify patients prior to starting any exercise program [74-81].

\section{Conclusions}

Implementing traditional variables with new parameters is diagnostically and prognostically important in patients undergoing ExT. ExT has an improved accuracy and is more clinically relevant when multiple risk parameters (ST-segment deviation, chest pain, exercise time, chronotropic competence, heart rate recovery, blood pressure recovery, ventricular arrhythmias) are incorporated into the final test result evaluation. These variables and related integrative scores, are important markers of current cardiovascular functional status, and also predict future morbidity and mortality. Novel variables and scores could help stratify risk, and so should be an integral part of the ExT report.

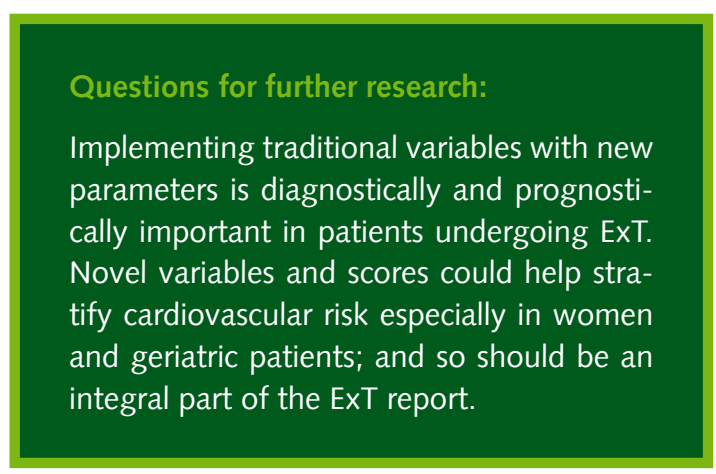

The review in brief

Clinical question This review aims at analysing the usefulness of exercise stress testing (ExT) as a diagnostic tool for evaluating patient's cardiovascular performance in different settings.

Type of review Narrative

Search of the literature PubMed, with keywords: exercise stress testing, acute coronary event, percutaneous coronary intervention, coronary artery bypass graft, dyspnea, chronotropic incompentence, heart rate recovery, functional capacity, women, elderly

Conclusions We found that ExT has an improved accuracy and is more clinically relevant when multiple risk parameters (ST-segment deviation, chest pain, exercise time, chronotropic competence, heart rate recovery, blood pressure recovery, ventricular arrhythmias) are incorporated into the final test result evaluation. The present review dealt with new variables/parameters that in the last few years added an incremental value to conventional analysis of exercise-induced angina or electrocardiographic changes

Limitations Search limited to the studies published in English 


\section{References}

1. Antman EM, Anbe DT, Armstrong PW, Bates ER, Green LA, Hand M, et al; ACC/AHA guidelines for the management of patients with ST-elevation myocardial infarction-executive summary: a report of the American College of Cardiology/American Heart Association Task Force on Practice Guidelines (Writing Committee to Revise the 1999 Guidelines for the Management of Patients with Acute Myocardial Infarction). Circulation 2004; 110: 588-636

2. Dominguez H, Torp-Pedersen C, Koeber L, Rask-Madsen C. Prognostic value of exercise testing in a cohort of patients followed for 15 years after acute myocardial infarction. Eur Heart J 2001; 22: $300-6$

3. Karlson BW, Sjölin M, Lindqvist J, Caidahl K, Herlitz J. Ten-year mortality rate in relation to observations at a bicycle exercise test in patients with a suspected or confirmed ischemic event but no or only minor myocardial damage: influence of subsequent revascularization. Am Heart J 2001; 141: 977-84

4. Topol EJ, Juni JE, O'Neill WW, Nicklas JM, Shea MJ, Burek K, et al. Exercise testing three days after onset of acute myocardial infarction. Am J Cardiol 1987; 60: 958-62

5. Senaratne MP, Smith G, Gulamhusein SS. Feasibility and safety of early exercise testing using the Bruce protocol after acute myocardial infarction. J Am Coll Cardiol 2000; 35: 1212-20

6. Branca G, Capodanno D, Capranzano P, Barbagallo R, Seminara D, Licciardello G, et al. Early discharge in acute myocardial infarction after clinical and angiographic risk assessment. J Cardiovasc Med (Hagerstown) 2008; 9: 858-61

7. Shaw LJ, Peterson ED, Kesler K, Hasselblad V, Califf RM. A meta-analysis of predischarge risk stratification after acute myocardial infarction with stress electrocardiographic, myocardial perfusion, and ventricular function imaging. Am J Cardiol 1996; 78: 1327-37

8. Villella M, Villella A, Barlera S, Franzosi MG, Maggioni AP. Prognostic significance of double product and inadequate double product response to maximal symptom-limited exercise stress testing after myocardial infarction in 6296 patients treated with thrombolytic agents. GISSI-2 Investigators. Gruppo Italiano per lo Studio della Sopravvivenza nell'Infarto Miocardico. Am Heart J 1999; 137: 443-52

9. Eisenberg MJ, Schechter D, Lefkovits J, Goudreau E, Deligonul U, Mak KH, et al; ROSETTA Investigators. Use of routine functional testing after percutaneous transluminal coronary angioplasty: results from the ROSETTA Registry. Am Heart J 2001; 141: 837-46

10. Beygui F, Le Feuvre C, Maunoury C, Helft G, Antonietti T, Metzger JP, et al. Detection of coronary restenosis by exercise electrocardiography thallium-201 perfusion imaging and coronary angiography in asymptomatic patients after percutaneous transluminal coronary angioplasty. Am J Cardiol 2000; 86: 35-40

11. Dori G, Denekamp Y, Fishman S, Bitterman H. Exercise stress testing, myocardial perfusion imaging and stress echocardiography for detecting restenosis after successful percutaneous transluminal coronary angioplasty: a review of performance. J Intern Med 2003; 253: 253-62

12. Scherhag A, Pfleger S, Haase KK, Sueselbeck T, Borggrefe M. Diagnostic value of stress echocardiography for the detection of restenosis after PTCA. Int J Cardiol 2005; 98: 191-7

13. Beregi JP, Bauters C, McFadden EP, Quandalle P, Bertrand ME, Lablanche JM. Exercise-induced ST-segment depression in patients without restenosis after coronary angioplasty. Relation to preprocedural impaired left ventricular function. Circulation 1994; 90: 148-55

14. Roffi M, Wenaweser P, Windecker S, Mehta H, Eberli FR, Seiler C, et al. Early exercise after coronary stenting is safe. J Am Coll Cardiol 2003; 42: 1569-73

15. Ferrari M, Schnell B, Werner GS, Figulla HR. Safety of deferring angioplasty in patients with normal coronary flow velocity reserve. J Am Coll Cardiol 1999; 33: 82-7 
16. Eisenberg MJ, Schechter D, Lefkovits J, Goudreau E, Deligonul U, Mak KH, et al; ROSETTA Investigators. Utility of routine functional testing after percutaneous transluminal coronary angioplasty: results from the ROSETTA registry. J Invasive Cardiol 2004; 16: 318-22

17. Bourassa MG, Pepine CJ, Forman SA, Rogers WJ, Dyrda I, Stone PH, et al. Asymptomatic Cardiac Ischemia Pilot (ACIP) study: effects of coronary angioplasty and coronary artery bypass graft surgery on recurrent angina and ischemia. The ACIP investigators. J Am Coll Cardiol 1995; 26: 606-14

18. Pepine CJ, Bourassa MG, Chaitman BR, Davies RF, Kerensky RA, Sharaf B, et al. Factors influencing clinical outcomes after revascularization in the asymptomatic cardiac ischemia pilot (ACIP). ACIP Study Group. J Card Surg 1999; 14: 1-8

19. Weiner DA, Ryan TJ, Parsons L, Fisher LD, Chaitman BR, Sheffield LT, et al. Prevalence and prognostic significance of silent and symptomatic ischemia after coronary bypass surgery: a report from the Coronary Artery Surgery Study (CASS) randomized population. J Am Coll Cardiol 1991; 18: 343-8

20. Weiner DA, Ryan TJ, Parsons L, Fisher LD, Chaitman BR, Sheffield LT, et al. Long-term prognostic value of exercise testing in men and women from the Coronary Artery Surgery Study (CASS) registry. Am J Cardiol 1995; 75: 865-70

21. Maddox TM. Preoperative cardiovascular evaluation for noncardiac surgery. Mt Sinai J Med 2005; 72: $185-92$

22. Kertai MD, Klein J, Bax JJ, Poldermans D. Predicting perioperative cardiac risk. Prog Cardiovasc Dis 2005; 47: 240-57

23. Freeman WK, Gibbons RJ. Perioperative cardiovascular assessment of patients undergoing noncardiac surgery. Mayo Clin Proc 2009; 84: 79-90

24. Cinello M, Nucifora G, Bertolissi M, Badano LP, Fresco C, Gonano N, et al. American College of Cardiology/American Heart Association perioperative assessment guidelines for noncardiac surgery reduces cardiologic resource utilization preserving a favourable clinical outcome. J Cardiovasc Med (Hagerstown) 2007; 8: 882-8

25. Devereaux PJ, Goldman L, Cook DJ, Gilbert K, Leslie K, Guyatt GH. Perioperative cardiac events in patients undergoing noncardiac surgery: a review of the magnitude of the problem, the pathophysiology of the events and methods to estimate and communicate risk. CMAJ 2005; 173: 627-34

26. Poldermans D, Hoeks SE, Feringa HH. Pre-operative risk assessment and risk reduction before surgery. J Am Coll Cardiol 2008; 51: 1913-24

27. Catena E, Mele D. Role of intraoperative transesophageal echocardiography in patients undergoing noncardiac surgery. J Cardiovasc Med (Hagerstown) 2008; 9: 993-1003

28. Wesorick DH, Eagle KA. The preoperative cardiovascular evaluation of the intermediate-risk patient: new data, changing strategies. Am J Med 2005; 118: 1413

29. Haffner SM, Lehto S, Ronnemaa T, Pyorala K, Laakso M. Mortality from coronary heart disease in subjects with type 2 diabetes and in nondiabetic subjects with and without prior myocardial infarction. N Engl J Med 1998; 339: 229-34

30. Albers AR, Krichavsky MZ, Balady GJ. Stress testing in patients with diabetes mellitus: diagnostic and prognostic value. Circulation 2006; 113: 583-92

31. Heller GV. Evaluation of the patient with diabetes mellitus and suspected coronary artery disease. Am J Med 2005; 118(Suppl 2): 9S-14S

32. Cosson E, Paycha F, Paries J, Cattan S, Ramadan A, Meddah D, et al. Detecting silent coronary stenoses and stratifying cardiac risk in patients with diabetes: ECG stress test or exercise myocardial scintigraphy? Diabet Med 2004; 21: 342-8

33. Fleg JL. Stress testing in the elderly. Am J Geriatr Cardiol 2001; 10: 308-13 
34. Molander U, Dey DK, Sundh V, Steen B. ECG abnormalities in the elderly: prevalence, time and generation trends and association with mortality. Aging Clin Exp Res 2003; 15: 488-93

35. Fleischmann KE. Noninvasive cardiac testing in the geriatric patient. Am J Geriatr Cardiol 2003; 12: $28-32$

36. Goraya TY, Jacobsen SJ, Pellikka PA, Miller TD, Khan A, Weston SA, et al. Prognostic value of treadmill exercise testing in elderly persons. Ann Intern Med 2000; 132: 862-70

37. Spin JM, Prakash M, Froelicher VF, Partington S, Marcus R, Do D, et al. The prognostic value of exercise testing in elderly men. Am J Med 2002; 112: 453-9

38. Gill TM, DiPietro L, Krumholz HM. Role of exercise stress testing and safety monitoring for older persons starting an exercise program. JAMA 2000; 284: 342-9.

39. McAuley P, Pittsley J, Myers J, Abella J, Froelicher VF. Fitness and fatness as mortality predictors in healthy older men: The Veterans Exercise Testing Study. J Gerontol A Biol Sci Med Sci 2009; 64: 695-9

40. Gibbons RJ, Balady GJ, Bricker JT, Chaitman BR, Fletcher GF, Froelicher VF, et al. ACC/AHA 2002 guideline update for exercise testing: summary article. A report of the American College of Cardiology/American Heart Association Task Force on Practice Guidelines (Committee to Update the 1997 Exercise Testing Guidelines). J Am Coll Cardiol 2002; 40: 1531-40

41. Mieres JH, Shaw LJ, Arai A, Budoff MJ, Flamm SD, Hundley WG, et al. Role of noninvasive testing in the clinical evaluation of women with suspected coronary artery disease: consensus statement from the Cardiac Imaging Committee, Council on Clinical Cardiology, and the Cardiovascular Imaging and Intervention Committee, Council on Cardiovascular Radiology and Intervention, American Heart Association. Circulation 2005; 111: 682-96

42. Wenger NK. Clinical characteristics of coronary heart disease in women: emphasis on gender differences. Cardiovasc Res 2002; 53: 558-67

43. Lloyd GW, Patel NR, McGing E, Cooper AF, Brennand-Roper D, Jackson G. Does angina vary with the menstrual cycle in women with premenopausal coronary artery disease? Heart 2000; 84: 189-92

44. Bokhari S, Bergmann SR. The effect of estrogen compared to estrogen plus progesterone on the exercise electrocardiogram. J Am Coll Cardiol 2002; 40: 1092-6

45. The Rotterdam ESHRE/ASRM-Sponsored PCOS Consensus Workshop Group. Revised 2003 consensus on diagnostic criteria and long-term health risks related to polycystic ovary syndrome. Fertil Steril 2004; 81: 19-25

46. Giallauria F, Orio F, Palomba S, Lombardi G, Colao A, Vigorito C. Cardiovascular risk in women with polycystic ovary syndrome. J Cardiovasc Med (Hagerstown) 2008; 9: 987-92

47. Rossi B, Sukalich S, Droz J, Griffin A, Cook S, Blumkin A, et al. Prevalence of metabolic syndrome and related characteristics in obese adolescents with and without polycystic ovary syndrome. $J$ Clin Endocrinol Metab 2008; 93: 4780-6

48. Orio F, Giallauria F, Palomba S, Cascella T, Manguso F, Vuolo L, et al. Cardiopulmonary impairment in young women with polycystic ovary syndrome. J Clin Endocrinol Metab 2006; 91: 2967-71

49. Giallauria F, Palomba S, Manguso F, Vitelli A, Maresca L, Tafuri D, et al. Abnormal heart rate recovery after maximal cardiopulmonary exercise stress testing in young overweight women with polycystic ovary syndrome. Clin Endocrinol (Oxf) 2008; 68: 88-93

50. Giallauria F, Orio F, Lombardi G, Colao A, Vigorito C, Tafuri MG, et al. Relationship between heart rate recovery and inflammatory markers in patients with polycystic ovary syndrome: a crosssectional study. J Ovarian Res 2009; 2: 3

51. Lanza GA, Mustilli M, Sestito A, Infusino F, Sgueglia GA, Crea F. Diagnostic and prognostic value of ST segment depression limited to the recovery phase of exercise stress test. Heart 2004; 90: $1417-21$ 
52. Morshedi-Meibodi A, Evans JC, Levy D, Larson MG, Vasan RS. Clinical correlates and prognostic significance of exercise-induced ventricular premature beats in the community: the Framingham Heart Study. Circulation 2004; 109: 2417-22

53. Frolkis JP, Pothier CE, Blackstone EH, Lauer MS. Frequent ventricular ectopy after exercise as a predictor of death. $N$ Engl J Med 2003; 348: 781-90

54. Leeper NJ, Dewey FE, Ashley EA, Sandri M, Tan SY, Hadley D, et al. Prognostic value of heart rate increase at onset of exercise testing. Circulation 2007; 115: 468-74

55. Vivekananthan DP, Blackstone EH, Pothier CE, Lauer MS. Heart rate recovery after exercise is a predictor of mortality, independent of the angiographic severity of coronary disease. J Am Coll Cardiol 2003; 42: 831-8

56. Messinger-Rapport B, Pothier Snader CE, Blackstone EH, Yu D, Lauer MS. Value of exercise capacity and heart rate recovery in older people. J Am Geriatr Soc 2003; 51: 63-8

57. Panzer C, Lauer MS, Brieke A, Blackstone E, Hoogwerf B. Association of fasting plasma glucose with heart rate recovery in healthy adults: a population-based study. Diabetes 2002; 51: 803-7

58. Chacko KM, Bauer TA, Dale RA, Dixon JA, Schrier RW, Estacio RO. Heart rate recovery predicts mortality and cardiovascular events in patients with type 2 diabetes. Med Sci Sports Exerc 2008; 40: 288-95

59. Jouven X, Empana JP, Schwartz PJ, Desnos M, Courbon D, Ducimetiere P. Heart-rate profile during exercise as a predictor of sudden death. N Engl J Med 2005; 352: 1951-8

60. Myers J, Tan SY, Abella J, Aleti V, Froelicher VF. Comparison of the chronotropic response to exercise and heart rate recovery in predicting cardiovascular mortality. Eur J Cardiovasc Prev Rehabil 2007; 14: 215-21

61. Laukkanen JA, Kurl S, Salonen R, Lakka TA, Rauramaa R, Salonen JT. Systolic blood pressure during recovery from exercise and the risk of acute myocardial infarction in middle-aged men. Hypertension 2004; 44: 820-5

62. McHam SA, Marwick TH, Pashkow FJ, Lauer MS. Delayed systolic blood pressure recovery after graded exercise: an independent correlate of angiographic coronary disease. J Am Coll Cardiol 1999; 34: 754-9

63. Grady TA, Chiu AC, Snader CE, Marwick TH, Thomas JD, Pashkow FJ, et al. Prognostic significance of exercise-induced left bundle-branch block. JAMA 1998; 279: 153-6

64. Hertzeanu H, Aron L, Shiner RJ, Kellermann J. Exercise dependent complete left bundle branch block. Eur Heart J 1992; 13: 1447-51

65. Bunch TJ, Chandrasekaran K, Gersh BJ, Hammill SC, Hodge DO, Khan AH et al. The prognostic significance of exercise-induced atrial arrhythmias. J Am Coll Cardiol 2004; 43: 1236-40

66. Mark DB, Shaw L, Harrell Jr FE, Hlatky MA, Lee KL, Bengtson JR et al. Prognostic value of a treadmill exercise score in outpatients with suspected coronary artery disease. N Engl J Med 1991; 325: 849-53

67. Alexander KP, Shaw LJ, Shaw LK, Delong ER, Mark DB, Peterson ED. Value of exercise treadmill testing in women. J Am Coll Cardiol 1998; 32: 1657-64

68. Myers J, Prakash M, Froelicher V, Do D, Partington S, Atwood JE. Exercise capacity and mortality among men referred for exercise testing. N Engl J Med 2002; 346: 793-801

69. Shishehbor MH, Litaker D, Pothier CE, Lauer MS. Association of socioeconomic status with functional capacity, heart rate recovery, and all-cause mortality. JAMA 2006; 295: 784-92

70. Shishehbor MH, Gordon-Larsen P, Kiefe CI, Litaker D. Association of neighborhood socioeconomic status with physical fitness in healthy young adults: the Coronary Artery Risk Development in Young Adults (CARDIA) study. Am Heart J 2008; 155: 699-705

71. Temporelli PL, Giannuzzi P. Cardiac rehabilitation after cardiac surgery: a valuable opportunity that should not be missed. Eur J Cardiovasc Prev Rehabil 2008; 15: 128-9 
72. Giannuzzi P, Temporelli PL, Maggioni AP, Ceci V, Chieffo C, Gattone M, et al; GOSPEL. GlObal Secondary Prevention strategiEs to Limit event recurrence after myocardial infarction: the GOSPEL study. A trial from the Italian Cardiac Rehabilitation Network: rationale and design. Eur J Cardiovasc Prev Rehabil 2005; 12: 555-61

73. Corrà U, Giannuzzi P, Adamopoulos S, Bjornstad H, Bjarnason-Weherns B, Cohen-Solal A, et al. Executive summary of the position paper of the Working Group on Cardiac Rehabilitation and Exercise Physiology of the European Society of Cardiology (ESC): core components of cardiac rehabilitation in chronic heart failure. Eur J Cardiovasc Prev Rehabil 2005; 12: 321-5

74. Fletcher GF, Balady GJ, Amsterdam EA, Chaitman B, Eckel R, Fleg J, et al. Exercise standards for testing and training: a statement for healthcare professionals from the American Heart Association. Circulation 2001; 104: 1694-1740

75. Giallauria F, Del Forno D, Pilerci F, De Lorenzo A, Manakos A, Lucci R, et al. Improvement of heart rate recovery after exercise training in older people. J Am Geriatr Soc 2005; 53: 2037-8

76. Giallauria F, De Lorenzo A, Pilerci F, Manakos A, Lucci R, Psaroudaki M, et al. Long-term effects of cardiac rehabilitation on end-exercise heart rate recovery after myocardial infarction. Eur J Cardiovasc Prev Rehabil 2006; 13: 544-50

77. Giallauria F, Lucci R, Pietrosante M, Gargiulo G, De Lorenzo A, D’Agostino M, et al. Exercise-based cardiac Rehabilitation improves heart rate recovery in elderly patients after acute myocardial infarction. J Gerontol A Biol Sci Med Sci 2006; 61: 713-7

78. Giallauria F, Cirillo P, Lucci R, Gargiulo G, De Lorenzo A, D’Agostino M, et al. Autonomic Dysfunction is associated with high mobility group box-1 levels in patients after acute myocardial infarction. Atherosclerosis 2010; 208: 280-4

79. Giallauria F, De Lorenzo A, Pilerci F, Manakos A, Lucci R, Psaroudaki M, et al. Reduction of N terminal-pro-brain (B-type) natriuretic peptide levels with exercise-based cardiac rehabilitation in patients with left ventricular dysfunction after myocardial infarction. Eur J Cardiovasc Prev Rehabil 2006; 13: 625-32

80. Giallauria F, Lucci R, De Lorenzo A, D’Agostino M, Del Forno D, Vigorito C. Favourable effects of exercise training on $\mathrm{N}$-terminal pro-brain natriuretic peptide plasma levels in elderly patients after acute myocardial infarction. Age Ageing 2006; 35: 601-7

81. Karapolat H, Eyigor S, Zoghi M, Yagdi T, Nalbantgil S, Durmaz B, et al. Effects of cardiac rehabilitation program on exercise capacity and chronotropic variables in patients with orthotropic heart transplant. Clin Res Cardiol 2008; 97: 449-56 